\section{RICH 1}

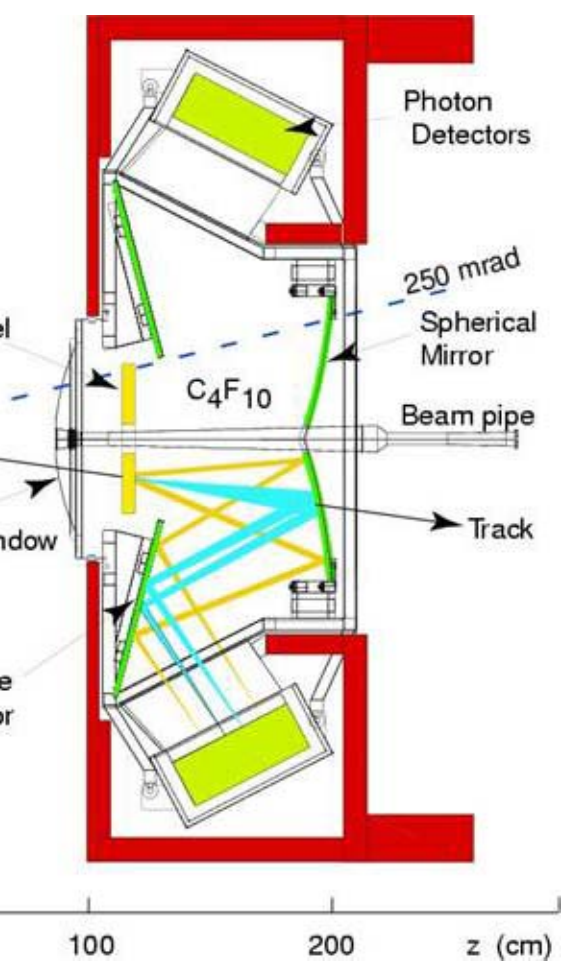

sel and $\mathrm{C}_{4} \mathrm{~F}_{10}$ radiators aration over 2-60 GeV/c $\mathrm{HCb}$ angular coverage

\section{HPDs}

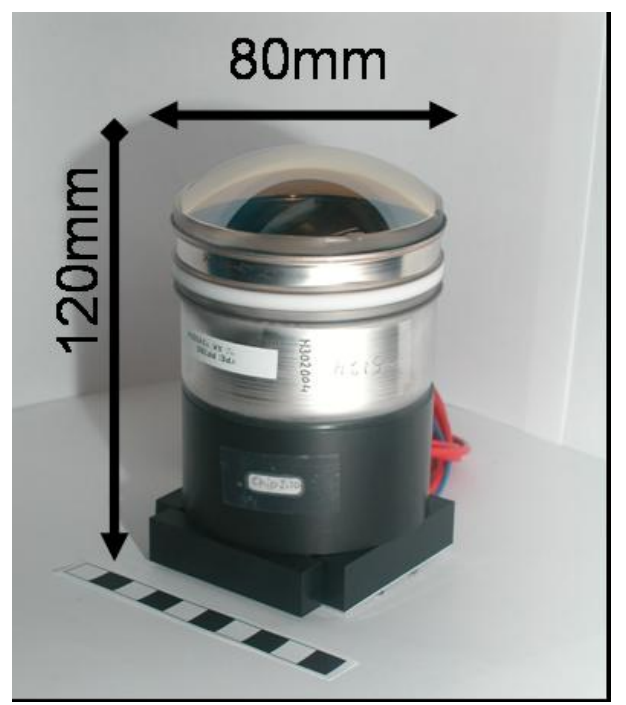

Mounted in close-packed array

$75 \mathrm{~mm}$ active diameter

$$
\text { Active area }>70 \%
$$

$2.5 \mathrm{~mm} \times 2.5 \mathrm{~mm}$ resolution

Operate at $40 \mathrm{MHz}$ (LHC bunch crossing frequency)

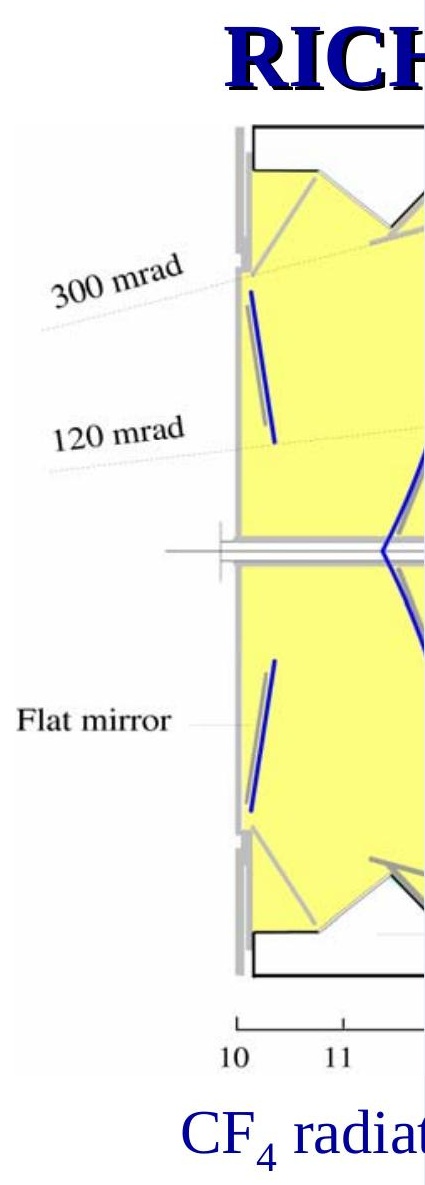

$\mathrm{K}-\pi$ separation over ? Reduced LHCb angl

\title{
Testbeam Setup
}

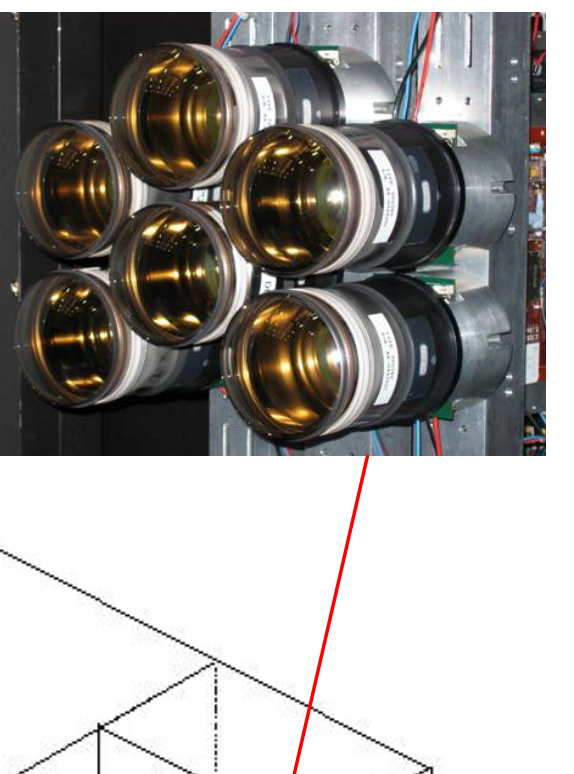

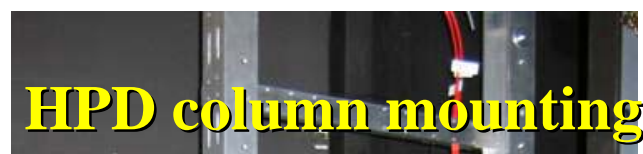

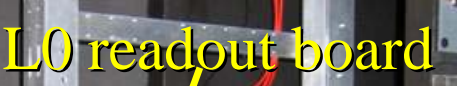

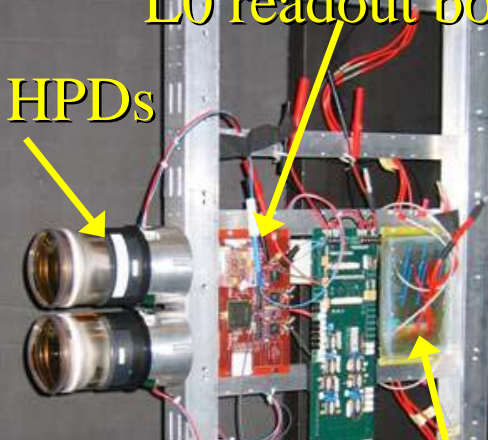

- Cluster of 6 HPDs in packed array, on 3 colu - Trigger on beam parti (provided by 2 scintilla upstream \& downstreai

- Particles arrive rando. burst $\rightarrow$ trigger is asyn with the 25 ns readout $c$ $\mathrm{LHCb}$ the trigger and $\mathrm{C}$ synchronised) 